\title{
It really was that bad, but I came back
}

See also news article at www.cmaj.ca/lookup/doi/10.1503/cmaj.109-4897, and editorial on page 1043 and at www.cmaj.ca/lookup /doi/10.1503/cmaj.141128

$\mathrm{H}$ ow did I get here? With apologies to Talking Heads, sometimes I ask myself, how DID I get here? Resurrecting a familymedicine practice in Tignish, Prince Edward Island, is what I'll be doing for the next few years. At the ripe old age of 59, I'm taking on something I would've never attempted 25 years ago. And I'm doing it 2500 miles away from home in a health service that is very different from the UK National Health Service I once loved with a mighty passion.

So what's so great about moving to Tignish? A little history might help. Seventeen years ago this month I was mooching around home, three months after a suicidal breakdown brought on by my second bout of major depression. Getting showered and dressed by $1 \mathrm{pm}$ each day was a major achievement, that's how bad I was, and that was after eight weeks in the psych unit, medication and the first few sessions of what eventually totally changed my life for the better - cognitive therapy with a first-class therapist. But, it was all looking pretty grim for a time. At the age of 43 , I was a washed-up, burnt-out wreck of my former self. I went from

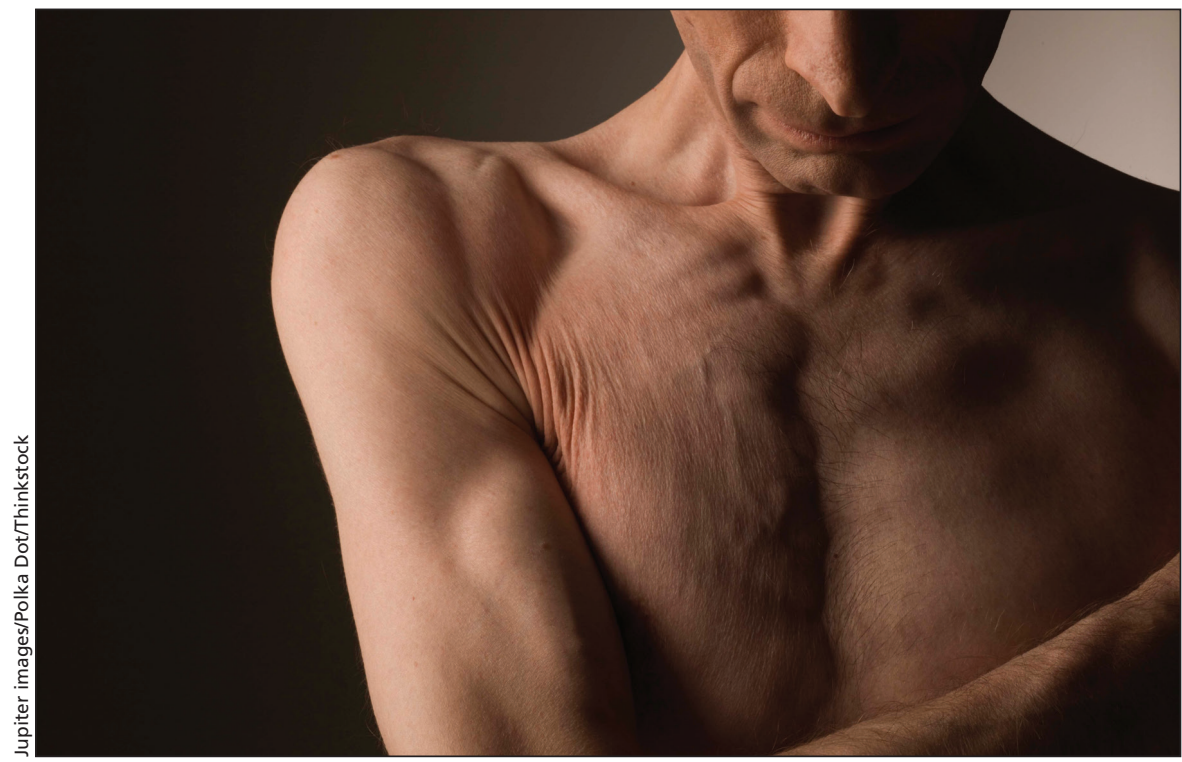

some of my patients experienced. Even before that first bout, I had been trying to cut down, to say "no" more often. Clearly, that hadn't worked.

And not too long after that, we got a new out-of-hours service going. We went from a one-in-four rural on-call rota and traipsing round the countryside doing home visits, to a much easier rota based in a large health centre. So things should have been better,

\section{It was all looking pretty grim for a time. At the age of 43, I was a washed-up, burnt-out wreck of my former self.}

überactive rural family physician to zero, with no realistic prospect of ever working in clinical medicine again.

Yes, it was really that bad. It was probably worse than you can imagine. I lived for my work. Even the dogs in the street knew that I worked far too hard. This was my second bout of major depression. I thought I had learned from the first episode, to cut down the work, to put a little emotional distance between me and the awful problems especially with my colleagues protecting me somewhat.

But things weren't better, and a year later madness washed over me one Sunday when a patient died on my watch. That was the final straw, I suppose. I had been up and down moodwise for a few months before that, but I had seen my family doctor and a psychiatrist who both thought it safe for me to carry on working.

So, what has changed? Well, I learned, eventually, that far too many of us get sucked into the health care system. We get chewed up, bled dry and spat out when we're of no further use. That's the way it goes, everywhere. Some places are worse than others. Some of us are more vulnerable than others.

Is Canada better, or have I learned to handle it better? Probably a bit of both. The family-doctor system in Canada is much less bureaucratic than the UK's, and it comes with very institutional balls and chains. The load on our backs comes more from our sense of professionalism, of responsibility to our patients. Thanks to cognitive therapy, I've found ways to lighten that load. I had a 13-year stretch of doing locums, mostly in PEI, with nothing worse, illness-wise, than one bad bout of sinusitis, and after that I felt confident enough in my own self-care skills to sign up for something a bit more permanent.

\section{Declan Fox MB MRCGP \\ Family Doctor \\ Tignish, PEI}

CMAJ 2014. DOI:10.1503/cmaj.141126

All editorial matter in CMAJ represents the opinions of the authors and not necessarily those of the Canadian Medical Association. 